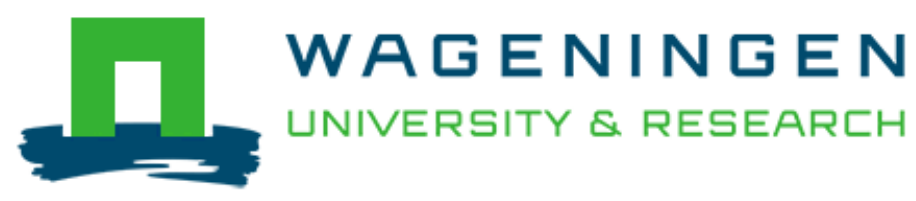

\title{
Membrane Selectivity Determines Energetic Losses for Ion Transport in Bioelectrochemical Systems
}

Sleutels, T. H. J. A., ter Heijne, A., Kuntke, P., Buisman, C. J. N., Buisman, C. J. N., \& Hamelers, H. V. M.

This article is made publically available in the institutional repository of Wageningen University and Research, under article $25 \mathrm{fa}$ of the Dutch Copyright Act, also known as the Amendment Taverne.

Article $25 \mathrm{fa}$ states that the author of a short scientific work funded either wholly or partially by Dutch public funds is entitled to make that work publicly available for no consideration following a reasonable period of time after the work was first published, provided that clear reference is made to the source of the first publication of the work.

For questions regarding the public availability of this article, please contact openscience.library@wur.nl.

Please cite this publication as follows:

Sleutels, T. H. J. A., ter Heijne, A., Kuntke, P., Buisman, C. J. N., Buisman, C. J. N., \& Hamelers, H. V. M. (2017). Membrane Selectivity Determines Energetic Losses for Ion Transport in Bioelectrochemical Systems. ChemistrySelect, 2(12), 3462-3470. https://doi.org/10.1002/slct.201700064 


\title{
Energy Technology \& Environmental Science
}

\section{Membrane Selectivity Determines Energetic Losses for lon Transport in Bioelectrochemical Systems}

\author{
Tom H. J. A. Sleutels, ${ }^{[[a]}$ Annemiek ter Heijne, ${ }^{[b]}$ Philipp Kuntke, ${ }^{[a]}$ Cees J. N. Buisman, ${ }^{[a, b]}$ and \\ Hubertus V. M. Hamelers ${ }^{[a]}$
}

Ion transport through ion exchange membranes in Bioelectrochemical Systems (BESs) is different from other electrochemical cells as a result of the complex nature of the electrolyte, as the electrolytes in BESs contain many other cations and anions than $\mathrm{H}^{+}$and $\mathrm{OH}^{-}$. Moreover, these other cations and anions are generally present in high concentrations and therefore determine the ion transport through the membrane. In this work, we provide a theoretical framework for understanding ion transport across ion exchange membranes in BESs. We show that the transport of cations and anions other than $\mathrm{H}^{+}$and $\mathrm{OH}^{-}$ determines the $\mathrm{pH}$ gradient between anode and cathode, and

\section{Introduction}

Bioelectrochemical Systems (BESs) are an emerging technology for the recovery of energy from wastewater, the production of chemicals from electrical current, storage of energy in acetate and the recovery of resources like for example recovery of ammonia. ${ }^{[1-6]}$ The basis of these technologies is the separation of the oxidation and reduction reaction where either one or both are catalyzed by microorganisms. At the anode an oxidation reaction takes place where both electrons and protons are produced. At the cathode, these protons can be consumed again in the reduction reaction. To compensate for the negative charge in the form of electrons that are produced at the anode and consumed at the cathode, ions have to travel through the electrolyte to maintain electroneutrality. Several ion exchange membranes (IEMs) have been tested for their suitability to transport specific ions selectively. For example, when protons are produced at the anode and consumed at the cathode a cation exchange membrane (CEM) is used to allow the protons to be transported from anode to cathode. Of course, this transport of ions goes at the expense of energy since it introduces an additional resistance for ion transport. Therefore, it has often been proposed that this separator can

[a] Dr. T. H. J. A. Sleutels, Dr. P. Kuntke, Prof. C. J. N. Buisman,

Dr. H. V. M. Hamelers

Wetsus, European centre of excellence for sustainable water technology Oostergoweg 9, 8911 CC Leeuwarden, The Netherlands

E-mail: tom.sleutels@wetsus.nl

[b] Dr. A. ter Heijne, Prof. C. J. N. Buisman

Sub-department of environmental technology Wageningen University Bornse weilanden 9, 6700 AA Wageningen, The Netherlands

Supporting information for this article is available on the WWW under https://doi.org/10.1002/slct.201700064 on top of that, also determines the membrane potential. Experimental data for microbial electrolysis cells with cation and anion exchange membranes are used to support the theoretical framework. In case of cation exchange membranes, the total potential loss consists of both the $\mathrm{pH}$ gradient and the concentration gradient of other cations, while in case of anion exchange membranes, the total potential loss is lower because part of the $\mathrm{pH}$ gradient loss can be recovered at the membrane. The presented work provides a better theoretical understanding of ion transport through ion exchange membranes in general and in BESs specifically.

be omitted to allow ions to travel more freely form the anode to cathode or vice versa. ${ }^{[7-9]}$ However, in many cases the inclusion of such an ion exchange membrane (IEM) offers benefits over its omission; It offers the possibility to keep anolyte, which in many cases is wastewater, and catholyte, where a pure product can be produced, separated. ${ }^{[10,11]}$ Next to this substrate/product separation, a higher Coulombic efficiency can be achieved, which is a requirement for BESs to become practically applicable for example as a wastewater treatment technology. ${ }^{[12,13]}$ Also, the use of a membrane offers the additional benefit of separating a compound of interest from the electrolyte through the ionic current that is induced by the electrical current, for example the separation and recovery of ammonia. ${ }^{[14-16]}$

The behavior of ions to pass through an IEM in BESs has been the subject of study for numerous years. Rozendal et al reported in 2006 that the use of a membrane gives rise to a $\mathrm{pH}$ gradient between anolyte and catholyte due to the composition of the electrolyte and the non-ideal selectivity of this membrane. ${ }^{[17]}$ Since, the concentration of cations in the anolyte other than protons is several orders of magnitude higher than that of protons themselves, these are preferably transported through the membrane in a much higher ratio compared to protons. When protons are consumed at the cathode these are replenished with other cations and the $\mathrm{pH}$ increases. From the concentration of protons in the anode and cathode compartment it can be calculated, using the Nernst equation, that for every $\mathrm{pH}$ unit difference between anode and cathode the energy loss in the electrode overpotential for every produced electron is $59 \mathrm{mV} .^{[18,19]}$ Testing of other IEMs like anion exchange membranes (AEM), bipolar membranes and charged mosaic membranes showed similar behavior in the transport of other 
ions than protons or hydroxyl and the development of a $\mathrm{pH}$ gradient between the anode and cathode compartment. ${ }^{[18,20,21]}$

Where ion transport across a membrane in the field of BESs is often considered an energy loss, the transport of ions across a membrane as a result of concentration differences between two electrolytes can be harvested in the form of electrical energy. This technology is generally being referred to as salinity gradient energy or Blue Energy. ${ }^{[14,22,23]}$ To harvest this energy, fresh and salt water are alternately flown through a compartment that is separated by an AEM on one side, and a CEM on the other. These membrane pairs (AEM and CEM) are stacked together, giving multiple compartments which are at the ends clamped together using two electrodes. Due to the concentration gradient, and the consequent potential difference, between fresh and salt water, the ions tend to move from the salt towards the fresh water. Because of the presence of the IEM, the ions can only move in one direction, the anions through the AEM and the cations through the CEM. This separation of charge can be harvested in an electrochemical reaction at the electrodes where the chemical potential difference can be transferred into electrical potential.

Similar to salinity gradient energy, in a BES, a concentration gradient develops between anode and cathode that could benefit the energy production, since the concentration of protons in the anolyte is generally higher than in the cathode. In theory, one would expect that this would result in energy recovery via the Donnan potential over the membrane, however in practice, this is not measured. The findings of these two fields of research thus seem to contradict.

To understand this seemingly contradiction, we analyze and elucidate the origin and mechanisms of the energy losses in a BES. To understand this mechanism, it is important to distinguish between energetic losses occurring at the electrodes (overpotential due to $\mathrm{pH}$ gradient) and the energetic losses due to ion transport (membrane potential). We will describe the ideal situation (perfectly selective membrane) in which only protons are transported and from that explain the non-ideal behavior of these systems. We use theory and experimental data to describe the origin of the energetic losses related to ion transport in BESs.

\section{Theory}

\section{lon transport through ion exchange membranes}

When current is produced by the electroactive biofilm, electrons flows from the anode to the cathode through the external electrical circuit. At the same time, protons are produced in the anodic oxidation reaction that, following the rules of electroneutrality, have to compensate for this transport of negative charge. Therefore, the sum of fluxes of the ionic charge $\left(\mathrm{j}_{\text {ions }}\right)$ through the membrane is equal to the produced current density $\left(\mathrm{j}_{\mathrm{e}}\right)$

$$
j_{e}=j_{\text {ions }}
$$

The total ion transport through the membrane consists of the transport of counter ions (opposite charge to the membrane) and co-ions (equal charge to the membrane). ${ }^{[2]}$ This ion transport causes an electroosmotic flow of water through the membrane. Water transport through the membrane can be important because it changes the concentration of ions in the electrolyte and thereby the energetic efficiency of the ion transport.

The flux of ions $\left(J_{\text {ions }}\right)$ through the membrane is described by the Nernst-Planck equation which is determined by (i) the concentration gradient of the specific ion and (ii) the electric field together with the charge of the specific ion ${ }^{[25]}$

$J_{\text {ions }}=-\mathbf{D}\left[\nabla c+\frac{F z c}{R T}(\nabla E)\right]$

Where $D$ is the diffusivity of the chemical species $\left(\mathrm{m}^{2} \mathrm{~s}^{-1}\right), \mathrm{c}$ is the concentration of the ionic species $\left(\mathrm{mol} \mathrm{L}^{-1}\right), \mathrm{R}$ is the universal gas constant $\left(8.314 \mathrm{Jmol}^{-1} \mathrm{~K}^{-1}\right), \mathrm{T}$ is the absolute temperature $(\mathrm{K})$ and $\nabla \mathrm{E}$ is the electric field of the electrolyte $(\mathrm{V}$ $\mathrm{m}^{-1}$ ) through which the ions move.

The migration term is determined by the electric field of the electrolyte (and membrane) and describes the energy change of ions of a specific charge moving through this field. When a positive ion moves through a negative field it dissipates energy while it gains energy when it moves through a positive electric field. For anions this is opposite, anions dissipate energy when they move through a positive field and gain energy when they move through a negative field. ${ }^{[25]}$

For the matter of simplification, in this manuscript we only distinguish between protons $(\mathrm{H})$ and hydroxyl ions $(\mathrm{OH})$ and the total concentration of other cations $(K)$ and other anions (A). $\mathrm{K}$ is chosen for cations, since $\mathrm{K}^{+}$is the most dominant cation, while in fact it also includes the total amount of $\mathrm{Na}^{+}$, $\mathrm{NH}_{4}^{+}, \mathrm{Ca}^{2+}$ and $\mathrm{Mg}^{2+}$. The anions (A) include $\mathrm{Cl}^{-}, \mathrm{PO}^{3-}$ (and $\mathrm{HPO}_{4}{ }^{2-}$ and $\left.\mathrm{H}_{2} \mathrm{PO}_{4}{ }^{-}\right), \mathrm{HCO}_{3}{ }^{-}$(and $\mathrm{CO}_{3}{ }^{2-}$ ), Acetate ${ }^{-}$and $\mathrm{SO}_{4}{ }^{2-}$.

\section{From start-up to steady-state conditions}

A full description of the experiments is given in the supporting information. Experiments were performed by applying a constant voltage (either 1 or $0.8 \mathrm{~V}$ ) to a Microbial Electrolysis Cell (MEC). At the start of the experiment, when anolyte and catholyte have the same $\mathrm{pH}$, the concentration of protons $(\mathrm{H})$ is equal in both anode and cathode. When closing the electric circuit, electrons flow from anode to cathode and consequently positive charge will move through the CEM. Since the concentration of $\mathrm{K}$ in the anolyte is about 10,000x higher than the concentration of $\mathrm{H}, \mathrm{K}$ is the preferred species to be transported (Figure $1 \mathrm{~A}$ ). Figure 1B shows the situation after a certain time period, before steady-state is reached. We see an elevated $\mathrm{K}$ concentration in the cathode as a result of cation migration, and a lower $\mathrm{H}$ concentration, due to the continuous reduction of protons in the cathode, compared to the initial situation. In this stage a combination of $\mathrm{H}$ and $\mathrm{K}$ is transported through the CEM. Finally, Figure $1 \mathrm{C}$ shows the steady-state concentrations, where the concentration of all cations $(K)$ has reached such a high level that for $K$ the migration term is in 


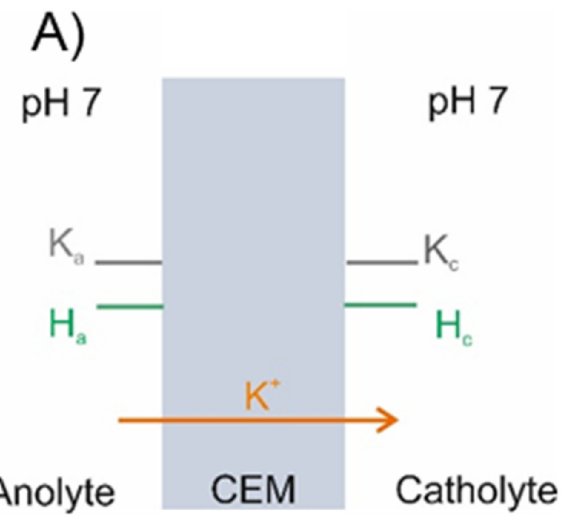

C)

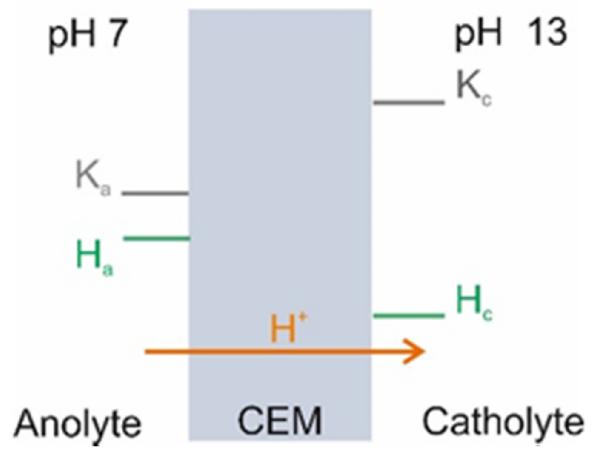

B)

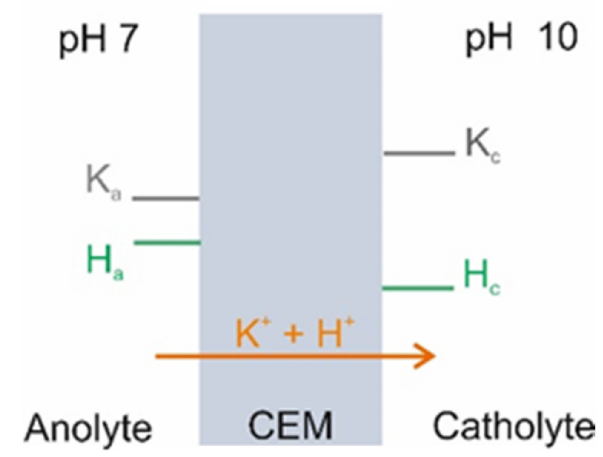

D)

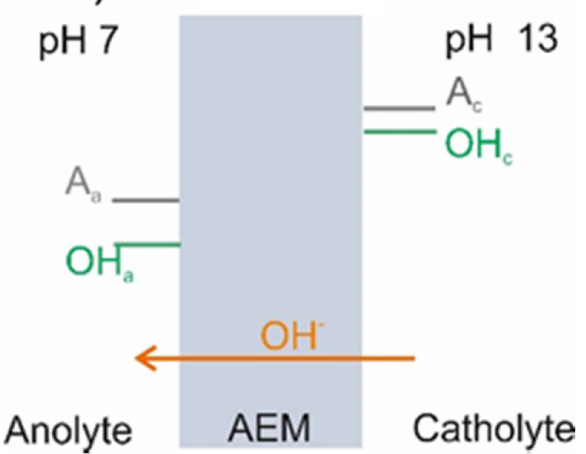

Figure 1. Development of the $\mathrm{pH}$ gradient in time. A) shows the concentrations of protons and other cations $(\mathrm{K})$ at the start of an experiment. B) Due to the flowing current mostly $\mathrm{K}$ will be transported to the cathode where still protons are consumed. Finally, C) shows that the concentration of $\mathrm{K}$ becomes so high in the cathode that it becomes energetically favorable to transport protons only. D) shows the final conditions for the AEM. Reaching steadystate mostly other anions are transported through the membrane until it reaches the point that only hydroxyl is transported through the AEM. equilibrium with the diffusional term. Therefore, it becomes energetically more favorable to transport $\mathrm{H}$, compared to transporting $\mathrm{K}$ against its concentration gradient.

For the AEM, the final composition at steady-state is shown in Figure 1D. To reach this steady state, first mostly cations (coion transport) are transported from anode to cathode. Although the membrane is positively charged, the cations contribute mostly to the charge transport in this phase. This is confirmed by the composition of the catholyte which finally consists of $\sim 45 \mathrm{mM}$ (see Table 1) of positive charge equivalents. ${ }^{[26]}$ In the final stage, the concentration of $\mathrm{OH}$ has reached such a high level in the cathode, as a result of proton consumption in the cathode reaction, that, in steady-state, $\mathrm{OH}$ becomes the sole ion responsible for charge transport through the AEM.
For both IEM steady-state conditions are being reflected in a constant $\mathrm{pH}$ gradient (constant $\mathrm{pH}$ in both anode and cathode), conductivity and current density within all parts of the system. These steady-state conditions have previously extensively been described in Sleutels et al (2013). ${ }^{[26]}$

\section{The membrane potential can be calculated from the anolyte and catholyte composition}

As described by equation 3 the ion transport is determined by the potential for migration and the potential for diffusion. The energy the transported ions dissipate or gain during transport through the ion exchange membrane is determined by the membrane potential and the direction of transport. A positive ion $(\mathrm{H}$ or $\mathrm{K})$ gains energy when it moves through a membrane

\begin{tabular}{|c|c|c|c|c|c|c|c|}
\hline & Applied voltage / V & $\begin{array}{l}\text { Ean / } \\
\text { V vs Ag/AgCl }\end{array}$ & $\begin{array}{l}\text { Ecat / } \\
\text { V vs Ag/AgCl }\end{array}$ & $\begin{array}{l}\mathrm{Ha} \mathrm{/} \\
\mathrm{mol} \mathrm{L}^{-1}\end{array}$ & $\begin{array}{l}\mathrm{Hc} / \\
\mathrm{mol} \mathrm{L}^{-1}\end{array}$ & $\begin{array}{l}\mathrm{Ka} / \\
\mathrm{mol} \mathrm{L}^{-1}\end{array}$ & $\begin{array}{l}\mathrm{Kc} / \\
\mathrm{mol} \mathrm{L}^{-1}\end{array}$ \\
\hline \multirow[t]{3}{*}{ CEM } & 1 & -0.34 & -1.15 & $6.810^{-7}$ & $2.010^{-14}$ & $4.610^{-2}$ & 0.65 \\
\hline & 0.8 & -0.40 & -1.06 & $1.110^{-7}$ & $3.010^{-14}$ & $4.610^{-2}$ & 0.55 \\
\hline & & & & $\begin{array}{l}\mathrm{OHa} \mathrm{/} \\
\mathrm{mol} \mathrm{L}^{-1}\end{array}$ & $\begin{array}{l}\mathrm{OHc} / \\
\mathrm{mol} \mathrm{L}^{-1}\end{array}$ & $\begin{array}{l}\mathrm{Aa} / \\
\mathrm{mol} \mathrm{L}^{-1}\end{array}$ & $\begin{array}{l}\mathrm{Ac} / \\
\mathrm{mol} \mathrm{L}^{-1}\end{array}$ \\
\hline \multirow[t]{2}{*}{ AEM } & 1 & -0.35 & -1.16 & $2.310^{-9}$ & 0.68 & $4.010^{-2}$ & $8.210^{-2}$ \\
\hline & 0.8 & -0.39 & -1.10 & $1.110^{-7}$ & 0.13 & $4.110^{-2}$ & 0.12 \\
\hline
\end{tabular}


with a positive potential from anode to cathode, while it dissipates energy when moving through a membrane with a negative potential from anode to cathode. For an anion $\mathrm{(OH}$ or A) this is opposite; it gains energy when moving through a membrane with a negative potential and dissipates energy when moving through a membrane with a positive potential.

The membrane potential $\left(E_{m e m}\right)$ is determined by the difference in concentration of ions in the anode $\left(m_{a}\right)$ and the concentration of ions in the cathode $\left(m_{c}\right)$, which can be calculated using the Nernst equation

$E_{\text {mem }}=\frac{R T}{n F} \ln \left(\frac{m_{a}}{m_{c}}\right)$

With $\mathrm{m}_{\mathrm{a}}=\mathrm{H}_{\mathrm{a}}+\mathrm{K}_{\mathrm{a}}$ and $\mathrm{m}_{\mathrm{c}}=\mathrm{H}_{\mathrm{c}}+\mathrm{K}_{\mathrm{c}}$

Where $\mathrm{Ha}$ and $\mathrm{Hc}$ are the concentrations of protons in the anolyte and catholyte respectively, Ka and Kc are the concentrations of other cations in the anolyte and catholyte.

The membrane potential can be calculated as the difference of the two Donnan potentials $\left(E_{D a}\right.$ and $E_{D C}$ ) on each side of the membrane. ${ }^{[25]}$ These two Donnan potentials are in turn determined by the difference in chemical potential of the electrolyte and the chemical potential of the ions inside the membrane

$E_{m e m}=E_{D a}-E_{D c}$

When we consider $\mathrm{K}$ as the total amount of other cations present, besides $\mathrm{H}$, in solution and thus the membrane, the composition of ions inside the membrane is determined by the charge of the membrane $(X)$ and can be described by

$-X+H_{a}^{m}+K_{a}^{m}=0-X+H_{c}^{m}+K_{c}^{m}=0$

Where $\mathrm{H}^{\mathrm{m}} \mathrm{a}$ and $\mathrm{H}^{\mathrm{m}}{ }_{\mathrm{c}}$ are the concentrations of protons inside the membrane on the anolyte and catholyte side respectively, $\mathrm{K}^{\mathrm{m}}{ }_{\mathrm{a}}$ and $\mathrm{K}^{\mathrm{m}}{ }_{\mathrm{c}}$ are the concentrations of other cations in the membrane on the anolyte and catholyte side. For the AEM where anions are being transported, A represents all other anions in solution next to $\mathrm{OH}$ which is the ion being transported in steady-state, the following is valid

$-X+O H_{a}^{m}+A_{a}^{m}=0-X+O H_{c}^{m}+A_{c}^{m}=0$

Where $\mathrm{OH}^{\mathrm{m}}{ }_{\mathrm{a}}$ and $\mathrm{OH}^{\mathrm{m}}{ }_{\mathrm{c}}$ are the concentrations of hydroxyl inside the membrane on the anolyte and catholyte side respectively, $A^{m}{ }_{a}$ and $A^{m}{ }_{c}$ are the concentrations of other anions inside the membrane on the anolyte and catholyte side. Applying these conditions, $E_{D a}$ and $E_{D c}$ can be calculated using

CEM : $\mathbf{E}_{\mathrm{Da}}=\frac{R T}{F} \ln \left(\frac{\mathbf{H}_{\mathrm{a}}+\mathbf{K}_{\mathrm{a}}}{\mathbf{X}}\right)$ and $\mathbf{E}_{\mathrm{Dc}}=\frac{R T}{F} \ln \left(\frac{\mathbf{H}_{\mathrm{c}}+\mathbf{K}_{\mathrm{c}}}{\mathbf{X}}\right)$

$\mathrm{AEM}: \mathrm{E}_{\mathrm{Da}}=\frac{R T}{F} \ln \left(\frac{O H_{\mathrm{a}}+A_{a}}{\mathrm{X}}\right)$ and $\mathrm{E}_{\mathrm{Dc}}=\frac{R T}{F} \ln \left(\frac{O H_{\mathrm{c}}+A_{\mathrm{c}}}{\mathrm{X}}\right)$
Where $X$ is the total charge of the membrane (Table 1 in supporting information) which is equal to the concentration of counter ions inside the membrane and is determined by the ion exchange capacity (IEC; in meq $\mathrm{g}^{-1} \mathrm{dry}^{-1}$ ) and swelling degree $(\sigma ;$ in $\%)$ of the membrane. This charge inside the membrane determines the distribution of ions inside the membrane, which is equal but of opposite charge compared to the membrane itself. Experimentally determined values for these membrane properties can be found in Table 1 in the supporting information. Together with the total concentration of ions in the electrolyte, $\mathrm{H}$ and $\mathrm{K}$ for the $\mathrm{CEM}$ and $\mathrm{OH}$ and $\mathrm{A}$ for the AEM, the charge inside the membrane determines the membrane potential.

\section{The energy applied to the system is used to drive the reactions at the electrodes and to transport ions}

The overall amount of work an MEC can perform as a result of the applied voltage, is not only determined by the difference in energy level of the electrons produced and consumed, but also by the difference in energy of the ions moving through the electrolyte (and thus through the membrane). So, the energy provided to the system through the applied voltage $\left(E_{a p p}\right)$ is divided over the equilibrium voltage $\left(E_{e q}\right)$, which is determined by the anode and cathode reactions, the internal resistance $\left(R_{\text {int }}\right)$ and the current density $(J)$.

$E_{\text {app }}=E_{\text {eq }}-J R_{\text {int }}$

When the anode and cathode potentials are calculated at the actual conditions, the internal resistance of the system is, almost entirely, determined by the ion transport through the system. The anode and cathode potentials can be calculated using

With $E_{c a t}=E_{c a t}^{0}+\frac{R T}{n F} \ln \left(\frac{H_{c}{ }^{2}}{p H_{2}}\right)$ and $E_{a n}=E_{a n}^{0}+\frac{R T}{n F} \ln \left(p C O_{2} \frac{\left[H_{a}\right]^{n}}{[A C]}\right)$

Combining and rewriting the equations above gives

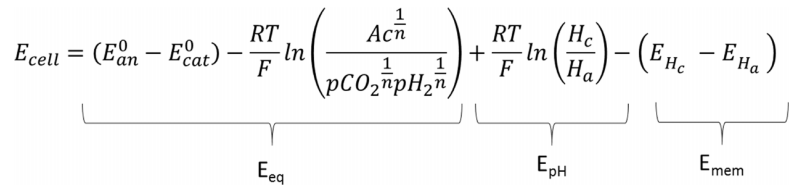

Where $\frac{R T}{F} \ln \left(\frac{H_{c}}{H_{a}}\right)$ describes the losses due to the actual $\mathrm{pH}$ at the electrodes and $\left(E_{H_{c}}-E_{H_{a}}\right)$ describes the additional losses due to the membrane potential (as described above). This membrane potential can also be measured as the difference between the reference electrode in the anode compartment and the reference electrode in the cathode compartment. ${ }^{[27,28]}$ For simplification, we assume here that the only potential change during ion transport through the membrane is due to the transport of counter-ions. The transport of co-ions and water through the membrane is neglected. ${ }^{[29]}$ Therefore, the 

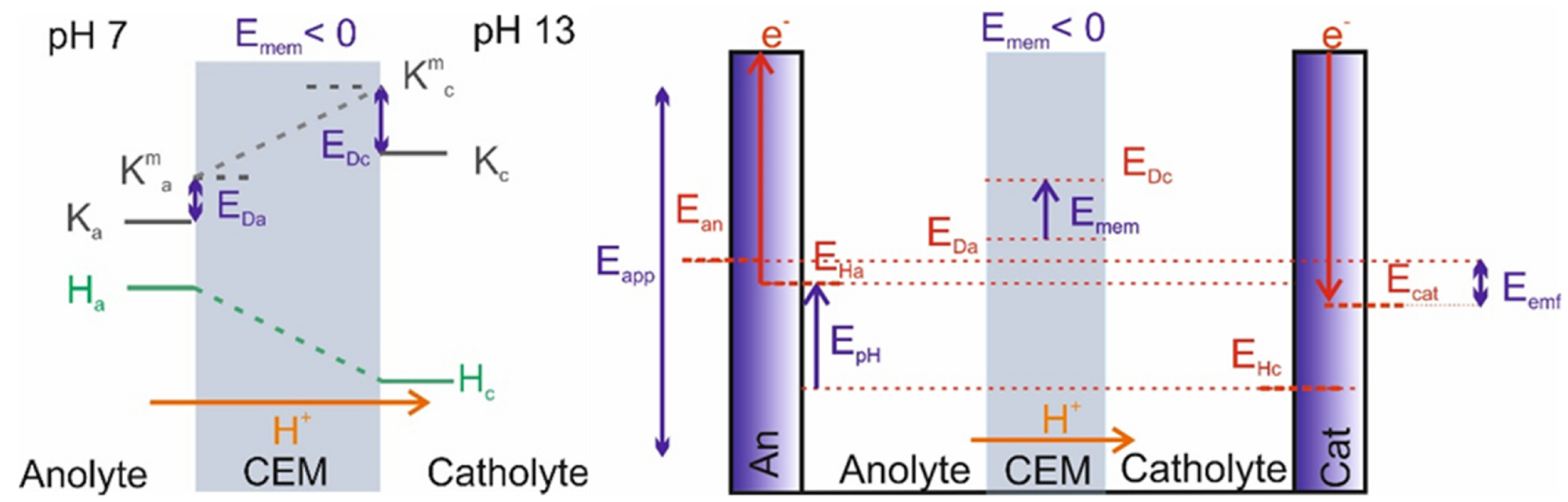

Figure 2. Steady-state ion concentrations in anolyte and catholyte in an MEC with a CEM and the consequent potential changes for the electrons and protons that are being produced and transported.

Nernst-Planck equation describes the transport of $\mathrm{H}$ and $\mathrm{K}$ through the $\mathrm{CEM}$ and $\mathrm{OH}$ and $\mathrm{A}$ through the AEM.

\section{Potential change of ions is determined by the selectivity of the membrane}

To study the effect of ion transport on the membrane and thus energetic efficiency of the system we have a closer look the potential changes for the transported ions under steady-state conditions. First, we examine a system with a CEM. As explained before (Figure 1), reaching steady-state a high concentration of $\mathrm{K}$ accumulates in the cathode and only protons are transported through the membrane (Figure 2). When we calculate the membrane potential using these ion concentrations (equation 4) we can see that the concentration of $\mathrm{K}$ in the cathode is a dominant factor in determining the membrane potential. This membrane potential would therefore be negative and not positive as it would be when only taking the $\mathrm{H}$ concentrations into account. A negative membrane potential implies that it would require energy to transport a positive ion like $\mathrm{H}$ through the CEM while the transport of the same ion $(H)$ would gain energy when calculating the membrane potential based on the concentration of $\mathrm{H}$. Due to this negative membrane potential, the energy lost in the electrode reactions, due to the $\mathrm{pH}$ gradient, is not regained in the membrane ion transport. Instead, an additional amount of energy, on top of the $\mathrm{pH}$ gradient, is lost for ion transport because the membrane potential is not determined by $\mathrm{H}$ but by $\mathrm{K}$.

The potential losses that occur in the system can be better understood by looking at all the changes in potential that occur within the system (Figure 2 and equation 11). The total potential applied to the system is depicted as $E_{a p p}$. This is the total amount of potential energy that is available to transport one mol of charge from anode to cathode. At the anode electrons are formed at a certain potential from the substrate $\left(E_{a n}\right)$ and at the same time protons are formed, also at a certain potential $\left(E_{\mathrm{Ha}}\right)$. At the cathode the protons react with electrons at a certain potential $\left(E_{\mathrm{cat}}\right)$. The difference between the anode and cathode potential is the minimum potential that has to be applied to have these reactions proceed $\left(E_{e m f}\right)$. The potential of the proton reacting at the cathode is determined by the

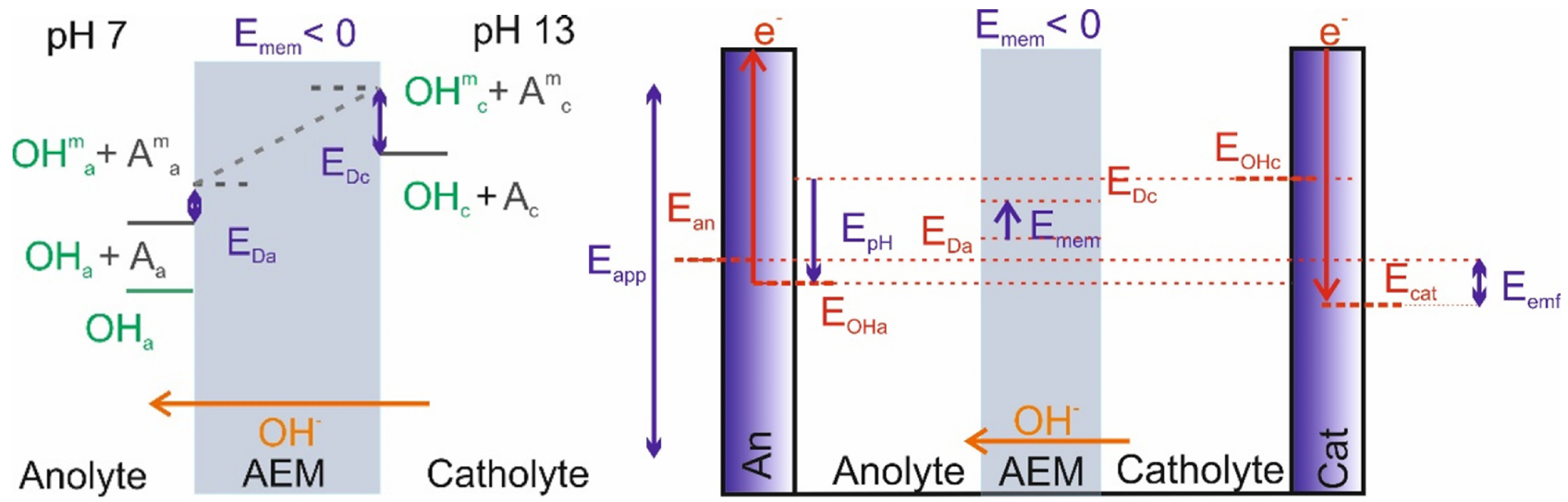

Figure 3. Steady-state ion concentrations in anolyte and catholyte in an MEC with an AEM and the consequent potential changes for the electrons and protons that are being produced and transported. 
concentration of protons in the cathode, which is negligibly low at $\mathrm{pH}$ 13. The difference in potential of the protons being produced at the anode and consumed at the cathode is determined by the difference in concentration of these protons (and thus by the $\mathrm{pH}$ difference). This potential loss is generally referred to as the $\mathrm{pH}$ gradient potential loss $\left(\mathrm{E}_{\mathrm{pH}}\right)$. In steadystate, protons are the only species transported through the membrane. For these protons to move from anode to cathode, they have to cross a membrane with a negative potential, that exists because of the gradient in concentration of $\mathrm{K}$. In this transport, the protons loose an additional amount of potential because of the negative membrane potential, on top of the potential lost as $\mathrm{pH}$ related overpotential at the electrodes.

For the MEC with an AEM the steady-state conditions are somewhat different from the system with a CEM. As can be seen in Figure 1D (and Table 1), around half of the anions in the catholyte are hydroxyl ions, while the other half consist of other anions. If we would calculate the membrane potential for this electrolyte composition, we can see that this membrane potential would still be, to a large extent (around 50\% (Table 1)), determined by the hydroxyl ions and only partly by the other anions. This is different from the CEM, where other cations than protons are dominant for membrane potential. This membrane potential for the AEM is negative, which implies that negative ions gain energy when they are transported through this membrane. Therefore, the difference in $\mathrm{pH}$ between anode and cathode, and its consequent chemical potential difference can partly be recovered in the negative potential of the negative ions moving through a membrane with a negative potential, resulting in lower potential losses across an AEM than across a CEM.

In analogy to the MEC with the CEM, a potential is applied to the cell, which is used to drive all the processes in the system. The electrons are produced at a potential from the substrate and consumed again to form hydrogen gas at another potential. The difference between anode and cathode potential, again is the $\mathrm{E}_{\text {emf }}$. The potential at which the $\mathrm{OH}$ is produced and consumed is again related to the $\mathrm{pH}$ through the dissociation constant of water $\left(\mathrm{K}_{\mathrm{w}}=10^{-14}\right)$. Therefore, the difference in the potential at which $\mathrm{OH}$ is produced at the cathode and the potential at which $\mathrm{OH}$ is consumed at the anode gives the $\mathrm{pH}$ gradient related losses. Part of these losses are regained in the transport of hydroxyl over the membrane with a negative potential. The entire $\mathrm{pH}$ gradient losses would be regained if the membrane potential was only determined by the $\mathrm{OH}$ in the cathode. However, due to the presence of the other anions, this potential is much lower than the value based on the $\mathrm{pH}$ gradient $(\sim 50 \%$ see Table 1$)$.

\section{Results and discussion}

Two MECs, one with a CEM and one with an AEM, were operated at two different applied voltages of 1.0 and $0.8 \mathrm{~V}$, until they reached steady-state conditions in ion transport through the membrane. At these conditions, the system with the CEM produced $2.7 \mathrm{~A} \mathrm{~m}^{-2}$ at $0.8 \mathrm{~V}$ and $7.2 \mathrm{~A} \mathrm{~m}^{-2}$ at $1.0 \mathrm{~V}$ while the system with the AEM produced $4.8 \mathrm{~A} \mathrm{~m}^{-2}$ at $0.8 \mathrm{~V}$ and

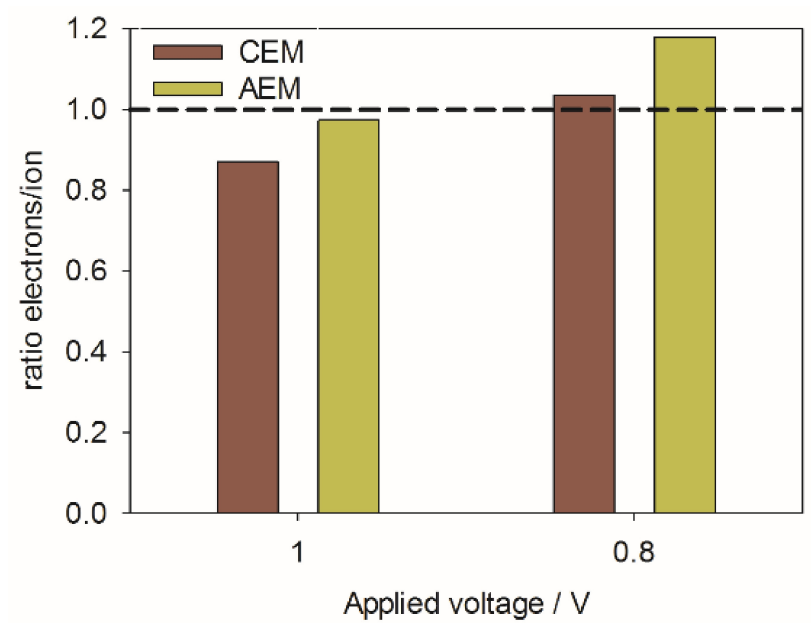

Figure 4. Ratio of the amount of electrons being produced compared to the ion transport through the IEM. A ratio of 1 indicates all the produced electrons are compensated by protons (CEM) or hydroxyl (AEM) transport through the membrane and steady-state conditions are confirmed.

10.2 A m-2 at $1.0 \mathrm{~V}$ (Table 1). The performance of these systems was reported before in Sleutels et al 2013. ${ }^{[26]}$ Here, we elaborate further on the performance of those systems by analyzing the membrane potential in steady-state conditions, based on measured ion concentrations.

\section{Steady-state ion transport occurs through protons and hydroxyl ions}

Figure 4 shows the ratio between the total protons (and proton carrying species as a function of $\mathrm{pH}: \mathrm{NH}_{4}{ }^{+}, \mathrm{Ac}^{-}, \mathrm{PO}_{4}{ }^{3-}, \mathrm{HPO}_{4}{ }^{2-}$, $\mathrm{H}_{2} \mathrm{PO}_{4}^{-}, \mathrm{HCO}_{3}^{-}, \mathrm{H}_{2} \mathrm{CO}_{3}, \mathrm{H}_{3} \mathrm{PO}_{4}$ and $\mathrm{NH}_{3}$ ) in the anode (inflow, outflow and production) and the total electrons flowing through the external circuit. A ratio of 1 means that all electrons that are produced are compensated by either protons or hydroxyl being transported through the membrane. This ratio was calculated for both the CEM and the AEM for the MEC operated at 2 different applied voltages of 1 and $0.8 \mathrm{~V}$. All calculated values are within a ratio of 0.87 and 1.18. and therefore this figure confirms that the systems were at steady state, because for the CEM most charge transport through the membrane was through $\mathrm{H}^{+}$, while for the AEM most charge transport was facilitated through $\mathrm{OH}^{-}$.

\section{Transport of ions is determined by the selectivity of the membrane}

Table 1 shows the practical conditions for all experiments. All numbers for ionic species represent actual measured concentrations. The concentrations of protons and hydroxyl are used to calculate the $\mathrm{pH}$ associated potential changes. The numbers for $\mathrm{K}$ and $\mathrm{A}$ are a summation of all positive species (for $\mathrm{K}$ ) and negative species (for $A$ ). These values are then used to calculate the actual membrane potentials. 

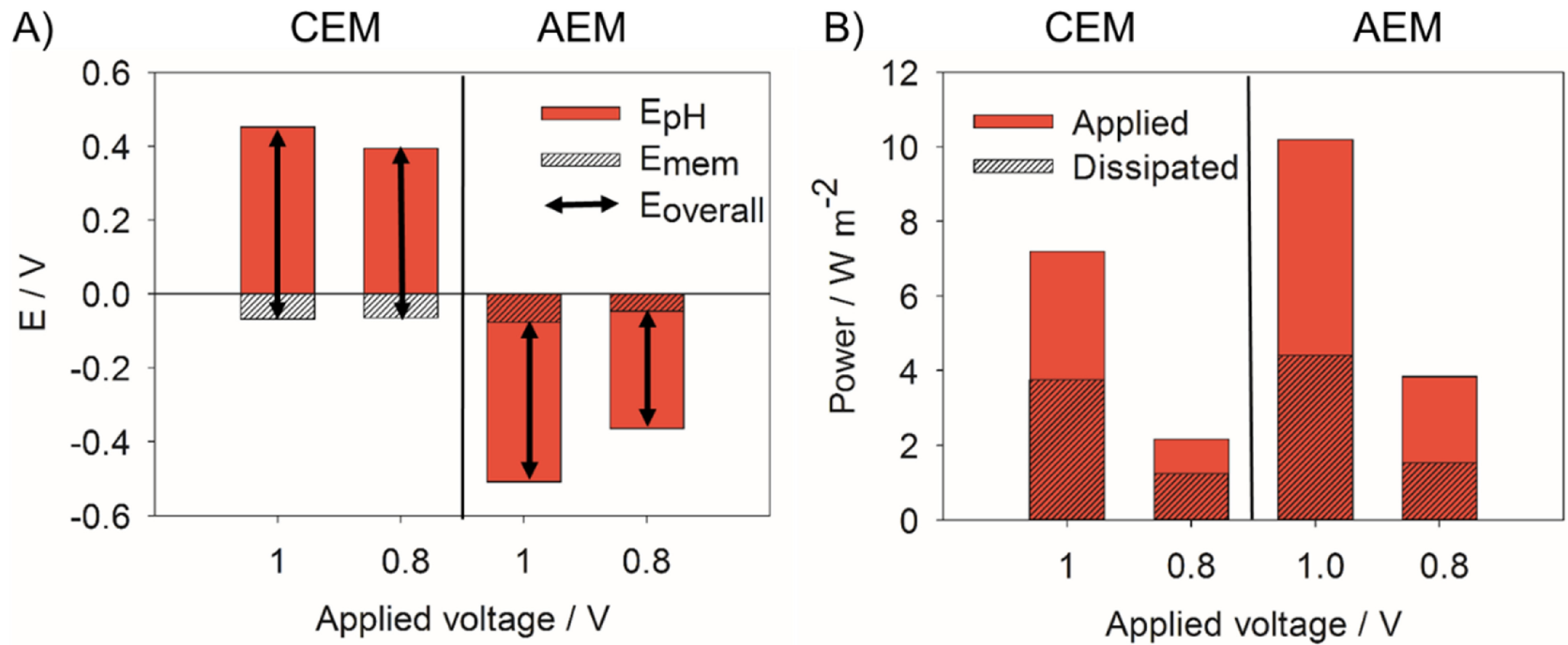

Figure 5. A

calculated values for the membrane potential and the losses related to the $\mathrm{pH}$ at the electrodes for experiments at an applied voltage of 1 and $0.8 \mathrm{~V}$ for $\mathrm{MECs}$ equipped with a CEM and an AEM. In case of a perfect selective membrane the $\mathrm{pH}$ related loss could be regained $\left(\mathrm{E}_{\mathrm{pH}}=-\mathrm{E}_{\mathrm{mem}}\right)$. In practice the overall energy loss in the system with the CEM is higher than the $\mathrm{pH}$ related potential due to the additional membrane potential. In the system with the $\mathrm{AEM}$ part of the $\mathrm{pH}$ related potential is regained in the membrane potential and therefore the overall energy loss is much lower compared to the system with the $\mathrm{CEM}$. Figure $5 \mathrm{~B}$ The total amount of power supplied to the system and the amount of power dissipated through membrane related processes (membrane potential and $\mathrm{pH}$ gradient).

Figure $5 \mathrm{~A}$ gives an overview of the potential losses in the system with a CEM and an AEM due to the $\mathrm{pH}$ gradient $\left(\mathrm{E}_{\mathrm{pH}}\right)$ and the membrane potential determined by the concentration of ions in the electrolyte $\left(E_{m e m}\right)$. The losses at the electrodes due to the $\mathrm{pH}$ difference between anolyte and catholyte can be considered as an indirect effect of the membrane selectivity. When the IEM would have been $100 \%$ selective for either protons or hydroxyl, the potential lost at the electrodes due to the $\mathrm{pH}$, would be regained in the membrane potential caused by the concentration gradient (of the protons or hydroxyl). As explained before in the theory section, other ions are transported over the membrane due to the non-ideal selectivity of the membrane. The concentration of these other ions, to a large extent, determines the membrane potential. In case of the CEM, the high concentration of other cations in the cathode, gives an additional loss over the membrane. Therefore, the overall amount of dissipated energy for protons going from anode to cathode is the sum of the loss at the electrodes due to the $\mathrm{pH}$ gradient and the membrane potential loss. For the $A E M$, only part of the $\mathrm{pH}$ gradient lost at the electrodes regained through the membrane potential. This amount of regained potential is lower due to the presence of the high concentration of other anions than $\mathrm{OH}$ in the cathode. The overall dissipated energy for ion transport through the AEM, therefore, is lower than the $\mathrm{pH}$ gradient potential loss. Compared to the system with the CEM the dissipated energy due to ion transport for the system with the AEM is much lower.

Figure 5B shows the total amount of power applied to the system through the applied voltage and the generated current density. This figure also shows the amount of power that is dissipated through membrane related processes. This dissipated power is a combination of (i) the power that is required to drive the electrode reactions, which is higher than the equilibrium potential due to the $\mathrm{pH}$ gradient and (ii) the power that is required for ion transport through the membrane. This figure shows that the relative contribution of the amount of dissipated power for the CEM is much higher compared to the AEM.

Figure 6 shows a comparison between the overall calculated (from Figure $5 \mathrm{~A}$ ) and the overall measured amount of

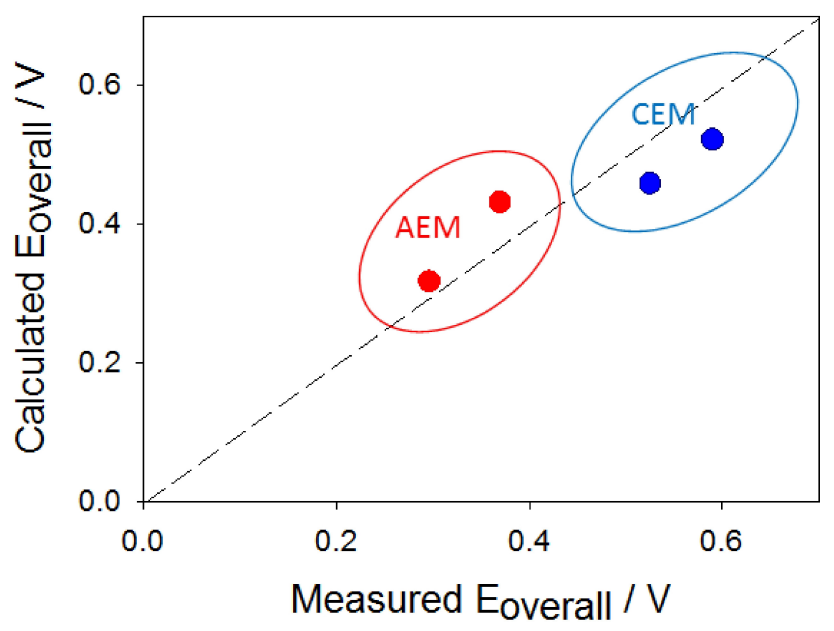

Figure 6. The overall calculated potential loss compared to the overall measured potential loss for the CEM and AEM. The dissipated energy for ion transport in the system with the AEM is lower than in the system with the CEM. 
potential lost in the system with the CEM and the system with the AEM. These calculated values for the membrane potential, together with the $\mathrm{pH}$ related potential loss are in the same order of magnitude as the values measured between the two reference electrodes in the anode compartment and in the cathode compartment, together with the $\mathrm{pH}$ related potential loss. In theory these measured values should correspond to the calculated values. The values are calculated from the ionic compositions of both electrolytes and under closed cell conditions. Therefore, the main difference between these values is caused by an additional loss for the ions being transported from one electrode to the other (ionic losses and concentration polarization). ${ }^{[30]}$

\section{Implications for applying ion exchange membranes in BESs}

In this paper we describe the energy losses associated with ion transport through IEM in BESs. Due to the transport of other ions than protons or hydroxyl a $\mathrm{pH}$ imbalance develops between anode and cathode. The energetic consequences of this $\mathrm{pH}$ imbalance are twofold. First, the $\mathrm{pH}$ of the electrolyte directly affects the overpotential for the reactions at both electrodes and therefore decrease the cell voltage for an MFC and increase the required cell voltage for MECs. Second, the presence of other ions in the cathode dominates the chemical potential changes of the actual ion transport over the membrane, and therefore determines the energy losses of transport of any ion across the membrane. The concentration of these ions on both sides of the membranes should be similar to keep the membrane potential minimized.

The analysis presented here reconfirms that an AEM is the most obvious choice for the use as separator in BESs based on energy efficiency since the relative energy loss related to the AEM compared to input (applied voltage) is much lower compared to the CEM. However, for some purposes, like e.g. recovery of ammonia from urine, a CEM is preferred. To be able to limit the membrane related potential losses, the membrane should be $100 \%$ selective. However, such a membrane is practically not available. ${ }^{[31]}$ Therefore, a more realistic strategy seems to be to change the concentration of ions in the electrolyte that contribute to the transport through the membrane like for example has been shown through the addition of $\mathrm{CO}_{2}$ to the catholyte. ${ }^{[32-34]}$ Another strategy could be to change the concentration of ions in the electrolyte which determine the membrane potential. In any case, a better understanding of ion transport across ion exchange membranes in the electrolytes typical for BESs and finding solutions to reduce the ion concentration gradients across the membranes are crucial to reduce the internal resistance and achieve high energy efficiencies in BESs.

\section{Acknowledgements}

This work was performed in the cooperation framework of Wetsus, European Centre of Excellence for Sustainable Water Technology (www.wetsus.eu). Wetsus is co-funded by the Dutch Ministry of Economic Affairs and Ministry of Infra- structure and Environment, the Province of Fryslân, and the Northern Netherlands Provinces. The authors like to thank the participants of the Resource Recovery research theme for the fruitful discussions and their financial support.

\section{Conflict of Interest}

The authors declare no conflict of interest.

Keywords: MFC - MEC - BES - MET • ion exchange membrane

[1] S. D. Molenaar, A. R. Mol, T. H. J. A. Sleutels, A. Heijne, Environ. Sci. Technol. Lett. 2016, 3, 144-1.

[2] K. Rabaey, R. A. Rozendal, Nat. Rev. Microbiol. 2010, 8, 706-16.

[3] B. E. Logan, B. Hamelers, R. Rozendal, U. Schröder, J. Keller, S. Freguia, P. Aelterman, W. Verstraete, K. Rabaey, Environ. Sci. Technol. 2006, 40, 5181-5192.

[4] B. E. Logan, D. Call, S. Cheng, H. V. M. M. Hamelers, T. H. J. A. J. A. Sleutels, A. W. Jeremiasse, R. A. Rozendal, Environ. Sci. Technol. 2008, 42, 8630-8640.

[5] M. Rodríguez Arredondo, P. Kuntke, A. W. Jeremiasse, T. H. J. A. Sleutels, C. J. N. Buisman, A. ter Heijne, Environ. Sci. Water Res. Technol. 2015, 1, 22-33.

[6] B. E. Logan, K. Rabaey, Science (80-. ). 2012, 337, 686 - 690.

[7] D. Call, B. E. Logan, Environ. Sci. Technol. 2008, 42, 3401-3406.

[8] H. Hu, Y. Fan, H. Liu, Water Res. 2008, 42, 4172-4178.

[9] S. Cheng, D. Xing, B. E. Logan, Biosens. Bioelectron. 2011, 26, 1913-1917.

[10] S. J. Andersen, T. Hennebel, S. Gildemyn, M. Coma, J. Desloover, J. Berton, J. Tsukamoto, C. Stevens, K. Rabaey, Environ. Sci. Technol. 2014, 48, 7135-7142.

[11] S. Gildemyn, K. Verbeeck, R. Slabbinck, S. J. Andersen, A. Prévoteau, K. Rabaey, Environ. Sci. Technol. Lett. 2015, 2, 325-328.

[12] T. Sleutels, S. Molenaar, A. Heijne, C. Buisman, Microorganisms 2016, 4, 7.

[13] Y. Fan, H. Hu, H. Liu, J. Power Sources 2007, 171, 348-354.

[14] B. E. Logan, M. Elimelech, Nature 2012, 488, 313-319.

[15] P. Kuntke, K. M. Śmiech, H. Bruning, G. Zeeman, M. Saakes, T. H. J. A. Sleutels, H. V. M. Hamelers, C. J. N. Buisman, Water Res. 2012, 46, 26272636.

[16] P. Kuntke, P. Zamora, M. Saakes, C. J. N. Buisman, H. V. M. V. Hamelers, Environ. Sci. Water Res. \&Technology 2016, 2, 261-265.

[17] R. A. Rozendal, H. V. M. Hamelers, C. J. N. Buisman, Environ. Sci. Technol. 2006, 40, 5206-5211.

[18] T. H. J. A. J. A. Sleutels, H. V. M. M. Hamelers, R. A. Rozendal, C. J. N. N. Buisman, Int. J. Hydrogen Energy 2009, 34, 3612-3620.

[19] F. Harnisch, U. Schröder, ChemSusChem 2009, 2, 921-926.

[20] R. A. Rozendal, T. H. J. A. Sleutels, H. V. M. Hamelers, C. J. N. Buisman, Water Sci. Technol. 2008, 57, 1757-1762.

[21] R. K. Jung, S. Cheng, S.-E. Oh, B. E. Logan, J. R. Kim, S. Cheng, S.-E. Oh, B. E. Logan, J. R. Kim, S. Cheng, et al., Environ. Sci. Technol. 2007, 41, 1004-1009.

[22] J. W. Post, H. V. M. Hamelers, C. J. N. Buisman, Environ. Sci. Technol. 2008, 42, 5785-5790.

[23] N. Y. Yip, D. Brogioli, H. V. M. Hamelers, K. Nijmeijer, Environ. Sci. Technol. 2016, acs.est.6b03448.

[24] M. Tedesco, H. V. M. Hamelers, P. M. Biesheuvel, J. Memb. Sci. 2016, 510, 370-381.

[25] Membranes International INC., lon Exchange Membranes, Royal Society Of Chemistry, Cambridge, 2014.

[26] T. H. J. A. Sleutels, A. Ter Heijne, C. J. N. Buisman, H. V. M. Hamelers, Int. J. Hydrogen Energy 2013, 38, 7201-7208.

[27] P. Długołecki, K. Nymeijer, S. Metz, M. Wessling, J. Memb. Sci. 2008, 319, 214-222.

[28] A. H. Galama, D. A. Vermaas, J. Veerman, M. Saakes, H. H. M. Rijnaarts, J. W. Post, K. Nijmeijer, J. Memb. Sci. 2014, 467, 279-291.

[29] W. J. van Egmond, M. Saakes, S. Porada, T. Meuwissen, C. J. N. Buisman, H. V. M. Hamelers, J. Power Sources 2016, 325, 129-139.

[30] P. Długołecki, P. Ogonowski, S. J. Metz, M. Saakes, K. Nijmeijer, M. Wessling, J. Memb. Sci. 2010, 349, 369-379. 
[31] A. Casadellà, O. Schaetzle, K. Loos, Macromol. Rapid Commun. 2016, 37, 858-864.

[32] C. I. Torres, H. S. Lee, B. E. Rittmann, Environ. Sci. Technol. 2008, 42, 87738777.

[33] J. J. Fornero, M. Rosenbaum, M. A. Cotta, L. T. Angenent, Environ. Sci. Technol. 2010, 44, 2728-2734.
[34] Y.-Q. Lan, J.-S. Li, Y.-J. Tang, C.-H. Liu, S.-L. Li, R.-H. Li, L.-Z. Dong, J.-C. Bao, Z.-H. Dai, J. Mater, et al., J. Mater. Chem. A Mater. energy Sustain. 2013, 0, $1-6$.

Submitted: January 12, 2017

Revised: April 11, 2017

Accepted: April 12, 2017 